\title{
LA PERVIVENCIA DE ESQUEMAS MÉTRICOS TRADICIONALES EN LAS CANCIONES POP ESPAÑOLAS
}

\section{THE SURVIVAL OF TRADITIONAL METRICAL SCHEMES IN THE SPANISH POP SONGS}

\author{
Clara I. Martínez Cantón \\ UNED (Madrid)
}

\begin{abstract}
Resumen: Las letras de canciones pop actuales en español no se ciñen normalmente a una estructura métrica clásica, ya que siguen un ritmo predeterminado por la música que hace que esto sea innecesario. Sin embargo, el prestigio de la poesía, unido a la fuerza de la tradición hace que todavía podamos rastrear algunos casos de letras de canciones que parecen compuestas bajo el prisma de la poesía, utilizando metros como endecasílabos, heptasílabos, etc.; y estrofas como cuartetos, serventesios, seguidillas, redondillas, etc. La utilización de estos moldes puede ser interpretada de muy diversas maneras: justificación artística, reivindicación de la inclusión de estas letras dentro del ámbito de la cultura con mayúsculas, o simple diálogo con la tradición.
\end{abstract}

Palabras clave: letras de canciones, estrofas, estructuras métricas, metros, música, pop, tradición.

Abstract: Spanish pop lyrics are not normally adhered to a classical metrical scheme, since they follow rhythm marked by the music. However, thanks to the prestige of poetry, along with 
the force of tradition, we can still track some lyrics that seem to be composed through the prism of poetry. They use classical verses such as hendecasyllables, heptasyllables, etc.; and stanzas as quatrains, limericks, etc. The use of these patterns in lyrics can be interpreted in many different ways: artistic justification, a claim to be included within the field of culture and arts, or simply, dialogue with tradition.

Key words: lyrics, stanzas, metrical structures, metros, music, pop, tradition. 


\section{Introducción}

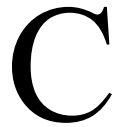

OMO ya he señalado en una publicación anterior ${ }^{1}$ las investigaciones y estudios de métrica en el ámbito hispánico rara vez se ocupan del campo de las letras de las canciones y su posible comparación con la métrica de la poesía. En este trabajo nos centraremos en la utilización en las letras de canciones actuales de estructuras típicas de la tradición poética española. No nos ocuparemos de la calidad literaria de dichas letras, lo que no excluye que exista en muchas de ellas, sino únicamente de la vertiente formal de las mismas. En esto coincidimos con la afirmación de Torrego Egido:

El texto de las canciones puede enmarcarse dentro del lenguaje poético. Con ello no se pretende afirmar nada acerca de la calidad literaria de los versos de las canciones: simplemente se quiere manifestar que el lenguaje utilizado por las canciones es diferente en su esencia al lenguaje común ${ }^{2}$.

En cuanto al corpus de canciones escogidas hemos de aclarar que nos ceñiremos exclusivamente a letras escritas por músicos españoles, en castellano, desde los años ochenta a la actualidad. Esto es debido a que hay que poner cierto límite dentro de un campo muy amplio. Estos límites se establecen porque cronológicamente se quiere abarcar la producción más reciente, y geográficamente porque nos ceñiremos así al ámbito nacional, que es también el más conocido para mí. En cuanto a los géneros hemos de aclarar que hemos optado por estudiar únicamente las

\footnotetext{
${ }^{1}$ Martínez Cantón, Clara I.: "Innovaciones en la rima: Poesía y rap". Rhythmica, Revista española de métrica comparada, 2010, VIII, pp. 67-94.

2 Torrego EgIDo, Luis Mariano: Canción de autor y educación popular (1960-1980). Madrid: Ediciones de la Torre, 1999, p. 76.
} 
letras de canciones pop o pop-rock por ser éstas, en términos generales, las más alejadas de la métrica de la poesía.

El punto clave de nuestro trabajo es observar si las estructuras poemáticas tradicionales son utilizadas con asiduidad en la canción, cuáles lo son más, y si esto crea vínculos con la poesía. Vemos que mientras que en la poesía las estructuras poemáticas tradicionales han experimentado una recesión en su uso (con la gran excepción del soneto ${ }^{3}$ ), en las letras de canciones, que no se encuentran ligadas normalmente a este tipo de moldes, sí encontramos estrofas o formas fijas típicas de la poesía. Ya otros investigadores habían hecho esta reflexión:

No debemos pasar de largo esta observación: mientras que la poesía culta (con pretensiones estéticas, formales e ideológicas, diría yo) se ha ido decantando, al menos de manera mediática y, en parte, académica, hacia el abandono de las formas heredadas o tradicionales, la poesía popular (y por poesía popular hay que entender durante el siglo xx la que sirve de punto de apoyo o de pretexto a la canción, desde Aristide Briand a Jacques Brel, pasando por Charles Trainet, Brassens, desde Edith Piaff a la última cantante francesa de cabaret, de Antonio Machín a Alejandro Sanz o Joaquín Sabina, pasando por todos los cantautores, en cualquier lengua, castellanos, catalanes o de música country, por toda la copla, en sus distintas variantes, el tango, el bolero, las rancheras, etc.), la poesía popular, es decir aquella mediante la cual "el pueblo" accede a los secretos de la poesía, en sentimiento, en imaginario, sigue aferrada a unas cuantas formas tradicionales, heredadas, inventadas y asumidas a lo largo de siglos por la colectividad. El pueblo, pues, sigue asumiendo la poesía y el poema desde la tradición. Y esta es una realidad que no desmienten [...] las diferentes formas de la música pop ${ }^{4}$.

Las letras de canciones toman de la poesía, muchas veces sin necesitarlo, patrones poéticos tradicionales, bien de manera consciente o inconsciente, como una forma de remitir a esa poesía

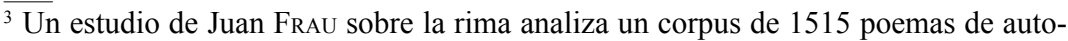
res españoles de 1975-2003 y encuentra que la forma más utilizada es el soneto, constituyendo un 3,4\% del total de los poemas y un $28 \%$ de los poemas rimados. (FraU, Juan: "La rima en el verso español". Rhythmica, Revista española de métrica comparada, 2004, II, pp. 109-136).

${ }^{4}$ Ansón Anadón, Antonio (coord.): Cómo leer un poema: estudios interdisciplinares, poesía, prosa, pintura, foto, cine, música, talleres, web. Zaragoza: Universidad de Zaragoza y Prensas Universitarias de Zaragoza, 2006, pp. 47-48. 
canónica, consagrada por la tradición, o también simplemente reproduciendo un ritmo o una estructura que resulta muy familiar en lengua castellana. Profundizar sobre estas semejanzas y diferencias puede resultar muy esclarecedor para ambos campos.

\section{Utilización de estructuras clásicas en canciones pop}

En este apartado trataremos de aproximarnos a las estructuras utilizadas para organizar la letra de una canción. En muchas ocasiones su relación con la poesía hace que sean altamente significativas, ya que su uso puede asegurar un esquema reconocible dentro de la tradición literaria. Esto supone además establecer una ligazón mayor o menor con esta tradición.

Para determinar la estructura de un poema concreto suelen tenerse en cuenta tres factores principales: número de versos que la forman, medida silábica de esos versos y posición de la rima. Estas reglas funcionan muy bien para clasificar poemas y canciones regulares con rima. Sin embargo cuando uno de estos criterios está menos definido (número de versos muy amplio, medidas silábicas dispares o desaparición de la rima), la definición y clasificación de la estructura poemática se vuelve más compleja.

Dado que en este trabajo buscamos únicamente hacernos eco de aquellas estructuras que remitan claramente a un modelo poético, nos limitaremos a señalar canciones que se organizan con arreglo a una estructura canonizada por la tradición, aunque permitan ciertas variaciones.

Como nos enfrentamos a un campo en el que voz y música se superponen encontraremos fenómenos que influirán en la correcta medida de los versos, y que tenemos que tener en cuenta para un correcto análisis. Así, en ocasiones encontraremos ciertas palabras o sílabas de relleno que señalaremos en el análisis, o ciertos versos que se introducen únicamente como repetición pero que no tienen valor dentro de lo que llamaríamos la estructura de esa letra.

\subsection{Pop, rock y pop-rock}

Estos géneros son quizás los que presentan un menor ${ }^{5}$ ajuste a

${ }^{5}$ En su estudio de la aplicación didáctica de estas letras dice GómEz CAPUZ: "Las letras de canciones pop presentan una acusada irregularidad métrica, a pesar de 
esquemas poemáticos tradicionales. La razón podemos buscarla quizás en el hecho de que se trata de un tipo de música que llega al ámbito hispánico a través del anglosajón, heredando con ello muchas de sus características. Otros autores ligan esta falta de regularidad en las letras al predominio de la música:

Esa ayuda que ofrece la música del Rock a sus textos consiste en dirigir, seguir, elevar o disminuir el ritmo de cada frase o de cada palabra con acordes de mayor o menor intensidad, según el efecto que se pretenda, pero parece claro que lo normal es que se capte primero el ritmo y después la letra, y que ésta se adecúe a aquél con mayor frecuencia que al contrario, porque lo que importa del Rock, sobre todo, es que es un ritmo, en cuanto a la música y en cuanto a una forma de entender la vida ${ }^{6}$.

Un excelente estudio de la adaptación que han de sufrir las letras en castellano para encajar dentro de unos ritmos que no le son propios es el llevado a cabo por Santiago Auserón (también conocido como Juan Perro y vocalista de la antigua banda Radio Futura), titulado "Métrica española y ritmo negro". Afirma el cantante:

$\mathrm{Al}$ encontrarse con la rítmica afroamericana amplificada por ciudades y pueblos - por obra de la radio y de la televisión, por las orquestas de baile- ambos grupos fónicos sufren cierta perplejidad. Pronto los primeros grupos de rock españoles intentan imitar el fraseo anglosajón, muy libre y flexible para comprimir ideas en un solo beat, y se encuentra con la papeleta de tener que sostener sílabas de más en los labios, yéndose de la mano que pulsa el instrumento. Para salir del compromiso, los cantantes suelen dislocar el acento natural de las palabras. Los fonemas del español son, por ende muy abiertos y rudos, lo que hace que toda licencia destaque en exceso. [...] Finalmente, cuando se aprende a calcar el dibujo de la frase en inglés, salen versos menos usuales, casi siempre cortos y de terminación aguda, y si son largos tienen frecuentemente nueve o diez sílabas, ni ocho ni once. La tentación de lo extranjero se queda en cercanía confusa. En la canción

estar subordinadas a esquemas musicales más o menos regulares". (GómEz CAPUZ, Juan: "Las letras de canciones de pop-rock español como textos poéticos: un modelo alternativo de educación literaria para E.S.O. y Bachillerato". Tonos digital: Revista electrónica de estudios filológicos, 2009, $\mathrm{n}^{\mathrm{o}}$ 17, p. 21).

${ }^{6}$ Pérez Pascual, Ángel: "La poesía y el rock". Pliegos de la Insula Barataria: Revista de creación literaria y de filología, 1994, nº 1, p. 148. 
en lengua romance es todavía perceptible el hiato entre la tradición y lo contemporáneo ${ }^{7}$.

Partiendo de estas afirmaciones sabrán valorarse en su justa medida los ejemplos que expondremos a continuación, y que no son tan llamativos como los que podríamos encontrar en la canción de autor.

Recogemos primero letras del ya nombrado grupo Radio Futura. Es significativa la canción "A cara o cruz", en la que encontramos una combinación de estrofas de cuatro versos con rimas independientes en cada estrofa y alternando rima cruzada y abrazada. El que podemos llamar estribillo de la canción está escrito en octosílabos con rima consonante abrazada:

$\begin{array}{ll}\text { Pongamos la cosa clara } & 8 \mathrm{a} \\ \text { busquemos alguna luz } & 8 \mathrm{~b} \\ \text { lo echamos a cara o cruz } & 8 \mathrm{~b} \\ \text { o lo hacemos por la cara. } & 8 \mathrm{a}\end{array}$

(RADIO FutURA, “A cara o cruz”, Memoria del porvenir)

Sin embargo las distintas estrofas que forman el texto de la canción están escritas en ocasiones en decasílabos y en otras en endecasílabos, mezclando además rima alterna y cruzada:

$\begin{array}{ll}\text { El sabor de la uva morena } & 10 \mathrm{~A} \\ \text { me gustó, el de la rubia también } & 10 \mathrm{~B} \\ \text { dicen que voy por la mala senda } & 10 \mathrm{~A} \\ \text { la tierra tiembla bajo mis pies. } & 10 \mathrm{~B} \\ & \\ & 11 \mathrm{~A} \\ \text { Y es que el amor es una enfermedad } & 11 \mathrm{~B} \\ \text { que una vez contraída no se cura } & 10 \mathrm{~B} \\ \text { y por más que uno quiera perdura } & 11 \mathrm{~A}\end{array}$

(RADIo Futura, “A cara o cruz", Memoria del porvenir)

Resulta llamativo asimismo el tono de la canción, sobre todo en su parte final, ya que se pueden percibir ciertas referencias a la lírica del Siglo de Oro:

\footnotetext{
7 Auserón, Santiago: "Métrica española y ritmo negro". Litoral, 2007, no 249, pp. 252-253.
} 
Vamos a ver dijo Don Rufio Datura ${ }^{8}$ por qué tenéis que perder la razón pues sin esfuerzo consigue natura

No esperes hoy la tormenta de ayer no dura siempre la pena de este infierno y aunque el azul del cielo no es eterno hasta mañana no vuelve a llover.

Es precisamente la existencia de una música en la que se apoya el texto la que hace que este tipo de irregularidades en la medida de los versos no sean tan visibles como podrían resultar en una simple lectura. La existencia de esta música y su ritmo son asimismo los causantes de que el tipo de endecasílabo más utilizado en estas letras sea precisamente el dactílico, tipo menos común en la poesía española. La tendencia a un ritmo ternario explica también la abundancia de decasílabos anapésticos.

Otras canciones de la misma banda también se basan en estos esquemas de cuartetos y serventesios endecasílabos. Recordemos la célebre "Veneno en la piel", cuyo estribillo está compuesto por cuatro endecasílabos dactílicos:

Dicen que tienes veneno en la piel

Y es que estás hecha de plástico fino

Dicen que tienes un tacto divino

Y quien te toca se queda con él
$11 \mathrm{~A}$

$11 \mathrm{~B}$

$11 \mathrm{~B}$

$11 \mathrm{~A}$

(RAdio FutURA, "Veneno en la piel", Memoria del porvenir)

La influencia de la poesía en este grupo se hace evidente, y encontramos incluso una versión del poema de Edgar Allan Poe “Annabel Lee". La canción no pretende conservar la métrica del original y se inclina más bien hacia versos de dieciséis sílabas con dos hemistiquios octosilábicos, aunque la irregularidad en la traducción/versión de Radio Futura es la norma.

Otro grupo cuya métrica y temática aparece ligada más claramente a la poesía es Mecano. Encontramos una serie de

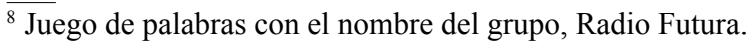


canciones que remiten a la lírica popular, y que reproducen asimismo su métrica. Es el caso de "Una rosa es una rosa", cuyas estrofas se organizan siguiendo un modelo de cuartetas octosilábicas con rima independiente y asonante:

\begin{tabular}{lc} 
Es por culpa de una hembra & $8 \mathrm{a}$ \\
que me estoy volviendo loco. & $8 \mathrm{~b}$ \\
No puedo vivir sin ella, & $8 \mathrm{a}$ \\
pero con ella tampoco. & $8 \mathrm{~b}$ \\
& \\
Y si de este mal de amores & $8 \mathrm{a}$ \\
yo me fuera pa la tumba, & $8 \mathrm{~b}$ \\
a mi no me mandéis flores, & $8 \mathrm{a}$ \\
que como dice esta rumba: & $8 \mathrm{~b}$ \\
\multicolumn{2}{c}{ (MecAno, "Una rosa es una rosa", Entre el cielo y el suelo) }
\end{tabular}

Este tipo de estructura remite claramente a la poesía y a la canción folklórica española. Dice Fernández Álvarez: "Entre las formas poéticas más usadas en la canción tradicional española cabe destacar, en primer lugar, la cuarteta. Es usada en multitud de géneros músico-vocales y es típica en jotas, folías y canciones de ronda",

Sin embargo, el estribillo de "Una rosa es una rosa" varía su métrica notablemente, pasando al heptasílabo como verso base:

$\begin{array}{ll}\text { Quise cortar la flor } & 7 \mathrm{a} \\ \text { más tierna del rosal, } & 7 \mathrm{~b} \\ \text { pensando que de amor } & 7 \mathrm{a} \\ \text { no me podría pinchar, } & 7 \mathrm{~b} \\ \text { y mientras me pinchaba } & 7- \\ \text { me enseñó una cosa } & 7 \mathrm{c} \\ \text { que una rosa es una rosa es una rosa... } & 12 \mathrm{c} \\ & \\ \text { Y cuando abrí la mano } & 7- \\ \text { y la dejé caer } & 7 \mathrm{~d} \\ \text { rompieron a sangrar } & 7- \\ \text { las llagas en mi piel } & 7 \mathrm{~d} \\ \text { y con sus pétalos } & 7- \\ \text { me las curó mimosa } & 7 \mathrm{c}\end{array}$

${ }^{9}$ Fernández Álvarez, Óscar: "Sobre las canciones del folklore musical en España". Revista de Folklore, Obra Social y Cultural de Caja España, 1994, nº 168, pp. 212. 
que una rosa es una rosa es una rosa...

(Mecano, "Una rosa es una rosa", Entre el cielo y el suelo)

Este tipo de métrica, aunque más original que la anterior parece basarse asimismo en esquemas tradicionales, si bien el cambio en una misma composición del octosílabo a heptasílabo podría parecer algo bastante extraño en las composiciones más canónicas.

Otra de las canciones de Mecano más conocidas y que presenta una mayor ligazón con la lírica es la titulada "Hijo de la luna". La temática, que gira en torno a la maternidad, el mundo gitano, la noche y la luna, relaciona esta canción directamente con el Romancero gitano de Lorca. La estructura formal del poema dista bastante, sin embargo, de ser la del romance. Se conservan, eso sí, las rimas asonantes y los versos de arte menor, pero estos son de distinto signo. Las estrofas están formadas por hexasílabos y heptasílabos según el siguiente patrón: $6(+4) 6$ (+4) 667667 . La rima no sigue el mismo patrón en todas las estrofas, pudiendo quedar versos sueltos, aparecer pareados, redondillas y otra serie de combinaciones:

$\begin{array}{ll}\text { tendrás a tu hombre//piel morena } & 6+4 \mathrm{~A} \\ \text { desde el cielo habló//la luna llena } & 6+4 \mathrm{~A} \\ \text { pero a cambio quiero } & 6 \mathrm{~b} \\ \text { el hijo primero } & 6 \mathrm{~b} \\ \text { que le engendres a él } & 7 \mathrm{c} \\ \text { que quien su hijo inmola } & 6 \mathrm{~d} \\ \text { para no estar sola } & 6 \mathrm{~d} \\ \text { poco le iba a querer } & 7 \mathrm{c}\end{array}$

(Mecano, "Hijo de la luna", Entre el cielo y el suelo)

El estribillo de esta canción sí adopta una métrica más cercana a la de las canciones populares:

Luna quieres ser madre

Y no encuentras querer

Que te haga mujer

Dime luna de plata

Qué pretendes hacer

Con un niño de piel
$7-$

$7 \mathrm{a}$

$7 \mathrm{a}$

$7-$

$7 \mathrm{a}$

$7^{\mathrm{a}}$

(Mecano, "Una rosa es una rosa", Entre el cielo y el suelo) 
Podríamos asimilar esta estructura a una sextilla definida por Domínguez Caparrós como: "estrofa de seis versos de arte menor cuya rima puede adoptar variadas disposiciones" 10 , de tipo paralelo, pues se divide en dos partes de tres versos que ordena la rima de forma paralela.

La influencia lorquiana en las canciones pop y rock actuales ha sido siempre significativa. Uno de los ejemplos más claros podría ser el del grupo Marea, cuyo disco 28000 puñaladas se apoya en gran medida en sus composiciones, aunque sin seguir en ningún caso la métrica. Encontramos incluso una versión musicada del "Romance de la Guardia Civil española".

Los Planetas, grupo de origen granadino, recogen en su último disco, "Una ópera egipcia", una serie de composiciones que remiten a poemas y cantes flamencos tradicionales. Es destacable la versión del "Romance de Juan de Osuna", obra del cantaor Manolo Caracol. A pesar de su nombre la composición no es exactamente un romance, sino que se organiza en estrofas de cuatro versos con rimas independientes de la siguiente forma: 8- 8a 8- 8a 8- 8b 8- 8b 8-8c 8- 8c. Lo más sorprendente quizás en este tema es encontrarnos con un estribillo en endecasílabos:

\begin{tabular}{ll} 
Los tormentos de mi negras duquelas & $11 \mathrm{~A}$ \\
No se los mando ni a mi enemigos & $11 \mathrm{~B}$ \\
Yo soñaba con clavito y canela & $11 \mathrm{~A}$ \\
Me despertaron pa' darme el castigo & $11 \mathrm{~B}$ \\
\multicolumn{2}{c}{ (Los Planetas, "Romance de Juan de Osuna", Una ópera } \\
egipcia)
\end{tabular}

La acentuación obligatoria del octosílabo en séptima sílaba y del endecasílabo en sexta u octava ha hecho que estos dos metros no aparezcan casi nunca juntos en una misma composición ${ }^{11}$. En parte también gracias a la música en esta canción se

${ }^{10}$ Domínguez Caparrós, José: Diccionario de métrica española. Madrid: Alianza, 2007 ( $1^{\text {a }}$ ed., 1985$)$, p. 387.

${ }^{11}$ La concordancia o discordancia entre los distintos metros ha sido un tema bastante tratado por los estudiosos. Isabel PARAíso, por ejemplo, afirma: "En general, los metros impares se mezclan sin discordancias, y los pares a su vez también. Por el contrario, la mezcla de pares e impares, sobre todo si son de medidas próximas (por ejemplo, de 7, 8 y 9 sílabas), produce choques e inestabilidad rítmica" (PARAíso, Isabel: La métrica española en su contexto románico. Madrid: Arco Libros, 
consigue combinar de manera natural dos metros que normalmente se han opuesto en tono y temática, pero que son, sin duda, los más utilizados de la lírica castellana.

Dentro de este mismo disco de Los Planetas se incluye también "Soy un pobre granaíno", que es, según la información encontrada en la web del disco, la adaptación de una colombiana (palo del flamenco). Sin embargo, aunque la colombiana suele caracterizarse porque el texto contiene seis versos de ocho sílabas, en esta canción encontramos un romance ${ }^{12}$ con algunas rimas ocasionales en los versos impares y algún verso no octosílabo:

$\begin{array}{ll}\text { Soy un pobre granaíno } & 8- \\ \text { soy un pobre granaíno } & 8- \\ \text { que vive en la serranía } & 8 \mathrm{a} \\ \text { y de noche bajo a verte } & 8- \\ \text { porque no puedo de día } & 8 \mathrm{a} \\ \text { que si de mi dependiese } & 8- \\ \text { nunca te abandonaría } & 8 \mathrm{a} \\ & \\ \text { sabes que por quererte } & 7- \\ \text { sabes que por quererte } & 7- \\ \text { me estoy jugando la vida } & 8 \mathrm{a} \\ \text { y en lugar de darte pena } & 8- \\ \text { creo que te da alegría } & 8 \mathrm{a} \\ \text { nadie va a quererte nunca } & 8- \\ \text { como yo a ti te quería } & 8 \mathrm{a} \\ \text { [... } & \\ & \\ \text { una rosa en un rosal } & 8- \\ \text { una rosa en un rosal } & 8- \\ \text { gasta mucha fantasía } & 8 \mathrm{a} \\ \text { viene el viento y la deshoja } & 8- \\ \text { ya está la rosa perdida } & 8 \mathrm{a} \\ \text { una rosa en un rosal } \\ \text { gasta mucha fantasía } & 8- \\ \text { abos Pla } & 8 \mathrm{a}\end{array}$

(Los Planetas, “Soy un pobre granaíno”, Una ópera egipcia)

2000, p. 113). En la práctica métrica encontramos que poetas como José Hierro sí han combinado en poemas metros como el endecasílabo y el hexasílabo o el decasílabo con el heptasílabo. Antonio Carvajal ha combinado también en sus liras en alguna ocasión endecasílabos con octosílabos.

${ }^{12}$ La repetición del primer verso de cada estrofa no impide su clasificación como romance. 
Este tipo de canciones recuperan el octosílabo como verso popular también para la canción pop española.

Por último destacaremos del disco de Los Planetas el tema "Siete faroles". Es una versión de una cantiña cordobesa, de la que coge una de las estrofas:

\begin{tabular}{lc} 
Como tú y yo lo vemos & $7-$ \\
no es de la misma forma & $7 \mathrm{a}$ \\
tú quieres fiesta & $5-$ \\
yo estoy en coma & $5 \mathrm{a}$ \\
tú piensas en espadas & $7-$ \\
yo en amapolas & $5 \mathrm{a}$ \\
como tú y yo lo vemos & $7-$ \\
no es de la misma forma & $7 \mathrm{a}$ \\
& \\
pregúntale al platero & $7-$ \\
pregúntale cuánto vale & $8 \mathrm{~b}$ \\
esos pendientes, & $5-$ \\
ese brillante & $5 \mathrm{~b}$ \\
ese anillo de plata & $7-$ \\
y ese colgante & $5 \mathrm{~b}$ \\
pregúntale al platero & $7-$ \\
pregúntale cuánto vale & $8 \mathrm{~b}$ \\
que cuánto vale & $5 \mathrm{~b}$ \\
que cuánto vale & $5 \mathrm{~b}$ \\
grabarte en los zarcillos & $7-$ \\
mis iniciales & $5 \mathrm{~b}$ \\
\multicolumn{1}{c}{ (Los PlaneTAs, "Siete faroles", Una ópera egipcia) }
\end{tabular}

Su métrica nos permitiría clasificarla como seguidilla, estrofa que define de la siguiente manera el Diccionario de métrica española de Domínguez Caparrós:

Combinación de cuatro versos, de los que el primero y el tercero son heptasílabos sueltos, y el segundo y el cuarto son pentasílabos que llevan rima asonante. Aunque es la forma canónica, cabe, sin embargo, señalar como modificaciones más corrientes: la fluctuación de los versos en su medida; la posibilidad de que la rima sea consonante, y de que los heptasílabos rimen entre sí también ${ }^{13}$.

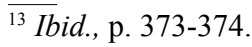


La gran diferencia estriba en el hecho de que la división en estrofas de cuatro versos no es tan clara en esta canción.

Acompañando a una relativa regularidad silábica, en la canción es frecuente encontrarse con letras que siguen una versificación por cláusulas métricas, debido, como ya comentábamos, a la influencia de la música. Es el caso de la canción "Del montón" de Sr. Chinarro:

\begin{tabular}{|c|c|}
\hline $\begin{array}{l}\text { Cerca fue del castillo, } \\
\text { el de San Sebastián, } \\
\text { de las barcas que amarran } \\
\text { a la orilla del mar. }\end{array}$ & $\begin{array}{l}7- \\
7 \mathrm{a} \\
7- \\
7 \mathrm{a}\end{array}$ \\
\hline $\begin{array}{l}\text { Nunca tú me quisiste, } \\
\text { yo vi ponerse el sol, } \\
\text { calabaza gigante: } \\
\text { ay, qué miedo me dio. }\end{array}$ & $\begin{array}{l}7- \\
7 \mathrm{a} \\
7- \\
7 \mathrm{a}\end{array}$ \\
\hline $\begin{array}{l}\text { Pudo ser un amor del montón, } \\
\text { pero todo el montón era mío. }\end{array}$ & $\begin{array}{l}10- \\
10-\end{array}$ \\
\hline $\begin{array}{l}\text { Y perdí la cabeza } \\
\text { y toqué pronto fondo. } \\
\text { Y se fue un pescador } \\
\text { al son del cante jondo. }\end{array}$ & $\begin{array}{l}7- \\
7 \mathrm{a} \\
7- \\
7 \mathrm{a}\end{array}$ \\
\hline $\begin{array}{l}\text { Yo miraba al castillo } \\
\text { y me creía Franz Kafka, } \\
\text { y escribí una canción } \\
\text { que acabé en una tasca. }\end{array}$ & $\begin{array}{l}7- \\
7 \mathrm{a} \\
7- \\
7 \mathrm{a}\end{array}$ \\
\hline $\begin{array}{l}\text { Pudo ser un amor del montón, } \\
\text { pero todo el montón era mío. }\end{array}$ & $\begin{array}{l}10- \\
10-\end{array}$ \\
\hline $\begin{array}{l}\text { Pudo ser, pero nunca fue nada } \\
\text { y en nada se queda el montón. } \\
\text { (SR. CHINARRO, }\end{array}$ & $\begin{array}{l}10- \\
10- \\
\text { Del } n\end{array}$ \\
\hline
\end{tabular}

La gran mayoría de los versos responde a un esquema anapéstico, por medio del cual se enlazan los versos heptasílabos y los decasílabos, por lo demás se sigue una estructura de estrofas de cuatro versos con rima asonante independiente en los versos pares. 
Por último, podemos también comentar la canción de Alejandro Sanz, "Te quiero y te temo", que se estructura como cuatro estrofas de ocho versos hexasílabos en los que ocasionalmente aparece algún quebrado de tres y todos los versos son monorrimos (con la excepción de dos versos en toda la canción que quedan sueltos):

$\begin{array}{lc}\text { Te siento y te vierto } & 6 \mathrm{a} \\ \text { te abro y te cierro } & 6 \mathrm{a} \\ \text { te advierto despierto } & 6 \mathrm{a} \\ \text { te miento } & 3 \mathrm{a} \\ \text { te evades, te espiro } & 6- \\ \text { te adhiero a mi cuerpo } & 6 \mathrm{a} \\ \text { te escapas, te dejo } & 6 \mathrm{a} \\ \text { te quiero y te temo } & 6^{\mathrm{a}} \\ \text { (ALEJANDRO SANZ, "Te quiero y te temo", El tren de los mo- } \\ \text { mentos) }\end{array}$

La particularidad de este tema reside, por una parte, en la posibilidad de dividir en dos hemistiquios trisílabos cada uno de los hexasílabos. Esto hace que el ritmo acentual coincida exactamente con el de cláusulas anfibráquicas. Además la rima entreteje prácticamente todos los versos e incluso varios de los hemistiquios.

Con esta sucinta selección de canciones hemos pretendido dar cuenta de los distintos modos en los en nuestro país el pop $\mathrm{y}$ rock actuales siguen en muchos casos unos patrones formales que los relacionan con la tradición poética. Aunque en algunas ocasiones esta utilización de estrofas y formas tradicionales se hace de manera no consciente, en otros la relación música-poesía se afianza por la imitación de un tono y un tema popular, o incluso por la influencia de una generación o un poeta en particular ${ }^{14}$.

\footnotetext{
${ }^{14}$ Afirma Gómez CAPUZ: "Otro de los grandes aspectos de imitación métrica en las canciones de pop consiste en la imitación de la poesía popular, recurso que también enlaza con la poesía romántica y de épocas posteriores (poesía neopopularista de la generación del 27). En las letras de muchas canciones de pop encontramos versos de arte menor (octosílabos o heptasílabos), rimas asonantes y cuartetas/ redondillas" (GÓMEZ CAPUZ, Juan: "Las letras de canciones de pop-rock español como textos poéticos...”, cit. p. 24).
} 


\section{Conclusiones}

Hemos pretendido dar a ver con este muestrario de canciones que muchas estrofas y estructuras poemáticas tipificadas en la poesía son recogidas por las letras actuales. Esto sucede principalmente en géneros musicales en los que la letra tiene una importancia superior a la música como puede ser la canción de autor, pero no sólo en esos ámbitos, sino que también en géneros como el rock o el pop la influencia de la poesía se deja notar.

Hasta cierto punto se asume que el lenguaje poético y el de las letras de canciones tienen algo en común, si bien, como decíamos, no siempre podemos hablar de calidad literaria. Temas (tópicos, referencias, etc.), figuras retóricas y moldes métricos encuentran un eco en las letras de canciones. Dice Zamora Pérez:

No deja de ser, a lo sumo, sorprendente, que en un ámbito musical, al que se le cuestiona su cualidad de cultura con mayúsculas, se dé precisamente la expresión de ideas y sentimientos, justo con aquellos mismos patrones formales-expresivos que habían dado lugar a las más bellas joyas literarias ${ }^{15}$.

Ha resultado interesante comprobar dicha afirmación. El análisis de varias canciones nos ha hecho ver que géneros como el pop y el rock se acercan con relativa poca frecuencia a esquemas prefijados por la tradición poética y, cuando lo hacen, casi nunca se ajustan a una plena regularidad, ya que la presencia de la música suple en muchos casos estas irregularidades. La libertad es así mayor que en la poesía regular, pero normalmente menor que en la poesía versolibrista, pues la música también impone ciertos esquemas.

Las formas que hemos encontrado que aparecen de forma más habitual son, por una parte, estrofas de cuatro versos, que podrían tomarse como las estrofas más tradicionales y habituales en la lírica popular. Como apuntan Varela, Moíño y Jauralde: "Las estrofas de cuatro versos aparecen desde los orígenes mismos de la poesía como una de las formas clásicas y espontáneas de organizar el poema"16. Los poemas en serventesios, cuartetos,

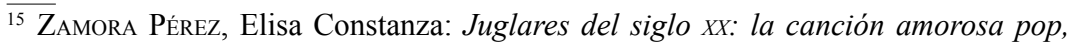
rock y de cantautor. Sevilla: Universidad de Sevilla, 2000, p. 34.

16 Varela, Elena; Moíño, Pablo; Jauralde Pou, Pablo: Métrica española. Madrid: 
cuartetas o redondillas buscan una forma de versificación natural. Así, aunque se utilice un recurso de ordenación tan rígido como la estrofa, hay una tendencia clara hacia este tipo estrófico que otorga naturalidad y cierta libertad en estas letras de canciones. Por otra parte es también muy generalizado el uso de series arromanzadas, lo que se explica por la gran influencia que esta forma poética ha tenido en nuestra tradición poética.

Una de las conclusiones más sorprendentes es la gran influencia del flamenco en la conformación de estas estrofas. En muchos casos podríamos pensar en este género musical como generador principal de estrofas y estructuras métricas tipificadas en la canción por delante del influjo de la poesía.

Cabe también destacar, por otro lado, la importancia de los patrones rítmicos anglosajones en los textos de canciones. Géneros como el rock y el pop son importados de este ámbito y copian sus ritmos en música y texto.

Aun así no cabe duda de que las letras de las canciones beben en parte de la tradición poética con la que guardan una relación de amor-odio, imitándola en algunos casos, transgrediéndola con su lenguaje o con enunciados abiertamente antipoéticos, etc. Para Pérez Pascual "a pesar de ese carácter rupturista del lenguaje del Rock, la influencia de la Poesía en esa música ha sido asumida con mucha mayor conciencia por parte de los cantantes modernos que la que haya podido ejercer el Rock en la Poesía", y defiende que existe "un Rock cuyas letras son, igual que en Poesía, estetizantes, metapoéticas, experimentales, etc., porque la analogía entre un tipo y otro de textos es demasiado evidente y porque, en el fondo, muchos rockeros han aspirado también a ser considerados como poetas"17. Esta afirmación es si cabe más cierta en otros tipos de música como la canción de autor, pero puede servir para los más variados géneros musicales.

El resultado es, al fin, un tipo de textos cuya relación con la poesía se hace en algunos casos más evidente que en otros, y que pueden permitirse ciertas libertades por su apoyo musical. Aunque no siempre se siguen patrones conocidos la interferencia entre géneros resulta muy enriquecedora y digna de estudio.

Castalia, 2005, p. 297.

17 Pérez Pascual, Ángel: "La poesía y el rock”, cit. p. 145. 


\section{Bibliografía utilizada}

ANSÓN ANADÓN, Antonio (coord.): Cómo leer un poema: estudios interdisciplinares, poesía, prosa, pintura, foto, cine, música, talleres, web. Zaragoza: Universidad de Zaragoza y Prensas Universitarias de Zaragoza, 2006

AUSERÓN, Santiago: "Métrica española y ritmo negro". Litoral, 2007, n 249, pp. 250-260.

DOMÍNGUEZ CAPARRÓS, José: Diccionario de métrica española. Madrid: Alianza, 2007 ( $1^{\mathrm{a}}$ ed., 1985).

FERNÁNDEZ ÁLVAREZ, Oscar: "Sobre las canciones del folklore musical en España". Revista de Folklore, Obra Social y Cultural de Caja España, 1994, n 168, pp. 212-216.

FRAU, Juan: "La rima en el verso español”. Rhythmica, Revista española de métrica comparada, 2004, II, pp. 109-136.

GÓMEZ CAPUZ, Juan: "Las letras de canciones de pop-rock español como textos poéticos: un modelo alternativo de educación literaria para E.S.O. y Bachillerato". Tonos digital: Revista electrónica de estudios filológicos, $2009, \mathrm{n}^{\circ} 17$.

MARTIINEZ CANTÓN, Clara I.: "Innovaciones en la rima: Poesía y rap". Rhythmica, Revista española de métrica comparada, 2010, VIII, pp. 67-94.

PARAIISO, Isabel: La métrica española en su contexto románico. Madrid: Arco Libros, 2000.

PÉREZ PASCUAL, Ángel: “La poesía y el rock". Pliegos de la Ínsula Barataria: Revista de creación literaria y de filología, 1994, nº 1, pp. 137-152.

TORREGO EGIDO, Luis Mariano: Canción de autor y educación popular (1960-1980). Madrid: Ediciones de la Torre, 1999.

VARELA, Elena; MOÍÑO, Pablo; JAURALDE POU, Pablo: Métrica española. Madrid: Castalia, 2005.

ZAMORA PÉREZ, Elisa Constanza: Juglares del siglo XX: la canción amorosa pop, rock y de cantautor. Sevilla: Universidad de Sevilla, 2000.

\section{Discografía}

ALEJANDRO SANZ: El tren de los momentos. Warner, 2006.

LOS PLANETAS: Una ópera egipcia. Sony Music, 2010.

MECANO: Entre el cielo y el suelo. Ariola, 1986.

RADIO FUTURA: Memoria del porvenir. Ariola BMG, 1998.

SR. CHINARRO: El mundo según. Mushroom Pillow, 2006. 